\title{
ChemComm
}

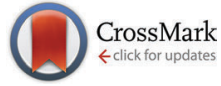

Cite this: Chem. Commun., 2015, 51, 9789

Received 13th April 2015, Accepted 6th May 2015

DOI: $10.1039 / \mathrm{c5cc03061g}$

www.rsc.org/chemcomm

\section{Photoinduced electron transfer in a supramolecular triad produced by porphyrin anion-induced electron transfer from tetrathiafulvalene calix[4]pyrrole to $\mathrm{Li}^{+} \mathrm{aC}_{60}{ }^{\dagger}$}

\author{
Christina M. Davis, ${ }^{a}$ Kei Ohkubo, ${ }^{\text {bc }}$ Aaron D. Lammer, ${ }^{a}$ Dong Sub Kim, ${ }^{a}$

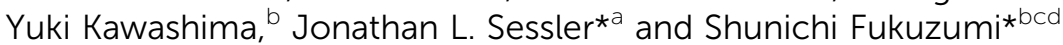

Binding of a porphyrin carboxylate anion (1) to tetrathiafulvalene calix[4]pyrrole (TTF-C4P) results in electron transfer from TTF-C4P to $\mathrm{Li}^{+} \mathrm{aC}_{60}$ to produce the charge-separated state $\left(1 / \mathrm{TTF}-\mathrm{C} 4 \mathrm{P}^{\circ} / \mathrm{Li}^{+} \mathrm{CC}_{60^{\circ}}\right)$ in benzonitrile. Upon photoexcitation of 1 , photoinduced electron transfer from the triplet excited state of 1 to TTF-C4P ${ }^{\circ+}$ occurs to produce the higher energy charge-separated state $\left(1^{0^{+}} / \mathrm{TTF}-\mathrm{C} 4 \mathrm{P} /\right.$ $\mathrm{Li}^{+}\left(\mathrm{CC}_{60^{\circ}}{ }^{-}\right)$, which decays to the ground state with a lifetime of $4.8 \mu \mathrm{s}$.

Three component supramolecular systems that can act as photoactive electron transfer (ET) systems are rare. In fact, we are unaware of any systems wherein three discrete redox active components are brought together through purely non-covalent interactions. Such constructs, to the extent they could be assembled, would provide an interesting complement to covalently linked ensembles or those involving a mixture of covalent and noncovalent linkages. Such putative self-assembled, three-component systems are also inherently rich in "molecular information" in that they might respond to a variety of different chemical stimuli. In principle, this would allow control of the supramolecular ET ensemble. Such assemblies are also of interest because they may allow a greater understanding of the determinants needed to create advanced molecular logic devices where an important readout parameter might be a photoinduced electron transfer (PET) event. ${ }^{1}$ Here we report a three-component supramolecular "triad" based on hydrogen bond anion recognition and $\pi-\pi$ donor-acceptor

\footnotetext{
a Department of Chemistry, The University of Texas, 105 E. 24th Street-Stop A5300, Austin, Texas, 78712-1224, USA. E-mail: sessler@cm.utexas.edu

${ }^{b}$ Department of Material and Life Science, Graduate School of Engineering, Osaka University and ALCA and SENTAN, Japan Science and Technology Agency (JST), 2-1 Yamada-oka, Suita, Osaka 565-0871, Japan

${ }^{c}$ Department of Bioinspired Science, Ewha Womans University, Seoul 120-750, Korea

${ }^{d}$ Faculty of Science and Technology, Meijo University and ALCA and SENTAN, Japan Science and Technology Agency (JST), Tempaku, Nagoya, Aichi 468-8502, Japan.E-mail: fukuzumi@chem.eng.osaka-u.ac.jp

$\dagger$ Electronic supplementary information (ESI) available: Experimental and spectroscopic details. See DOI: 10.1039/c5cc03061g
}

interactions. This system builds on two previous findings, namely that (1) thermal ET occurs from TTF-calix[4]pyrrole (TTF = tetrathiafulvalene) to lithium-encapsulated fullerene and (2) that photoinduced ET may be triggered by irradiating a TTFcalix[4]pyrrole-porphyrin carboxylate ensemble. ${ }^{2,3}$

Extensive efforts have so far been devoted to the design and synthesis of covalently linked electron donor-acceptor ensembles, including dyads, triads, tetrads and pentads, many of which have been shown to mimic the energy-transfer and electrontransfer processes seen in biological photosynthetic reaction centers. ${ }^{4-10}$ In this context, the use of non-covalent interactions, such as metal-ligand coordination, electrostatic effects and hydrogen bonds, has garnered considerable attention because they allow electron transfer donor-acceptor supramolecular dyads to be produced via self-assembly. ${ }^{3,10-14} \mathrm{~A}$ current challenge involves extending the chemistry of supramolecular dyads to create higher order constructs, such as supramolecular triads. ${ }^{15}$ To our knowledge, no reports have appeared that describe supramolecular electron donor-acceptor ensembles composed of three different components, perhaps because most non-covalent interactions are too weak to assemble three components at the same time. ${ }^{16}$

To address this challenge, we have created a supramolecular triad composed of a porphyrin anion (1), the radical cation of tetrathiafulvalene calix[4]pyrrole (TTF-C4P), and the radical anion of $\mathrm{Li}^{+}$-encapsulated $\mathrm{C}_{60}\left(\mathrm{Li}^{+} @ \mathrm{C}_{60}\right)$ (Fig. 1). These components bind to one another in a specific fashion via a combination of electrostatic and donor-acceptor interactions as shown in Fig. 2. We have examined the formation of the triad (1/TTF-C4P $\mathrm{P}^{+} / \mathrm{Li}^{+}$@ $\mathrm{C}_{60}{ }^{--}$) by monitoring porphyrin anion-induced electron transfer from TTF-C4P to $\mathrm{Li}^{+} @ \mathrm{C}_{60}$ in benzonitrile (PhCN). We also report the photodynamics of the supramolecular triad.

Upon mixing TTF-C4P and [ $\left.\mathrm{Li}^{+} @ \mathrm{C}_{60}\right] \mathrm{PF}_{6}$ in PhCN, no evidence of electron transfer was observed. This is consistent with an endergonic electron transfer process as inferred from the higher one-electron oxidation potential of TTF-C4P $\left(E_{\mathrm{ox}}=\right.$ $0.51 \mathrm{~V}$ vs. SCE) $)^{2,16}$ compared to the one-electron reduction potential of $\mathrm{Li}^{+} @ \mathrm{C}_{60}(0.14 \mathrm{~V} v s$. SCE $) .{ }^{17}$ Upon addition of 


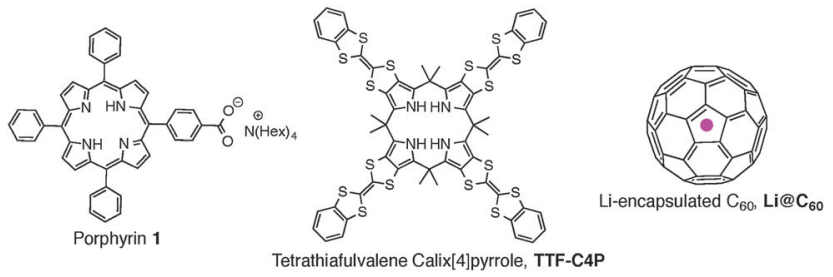

Fig. 1 Structures of porphyrin salt 1, tetrathiafulvalene calix[4]pyrrole (TTF-C4P), and $\mathrm{Li}^{+} \mathrm{aC}_{60}$.

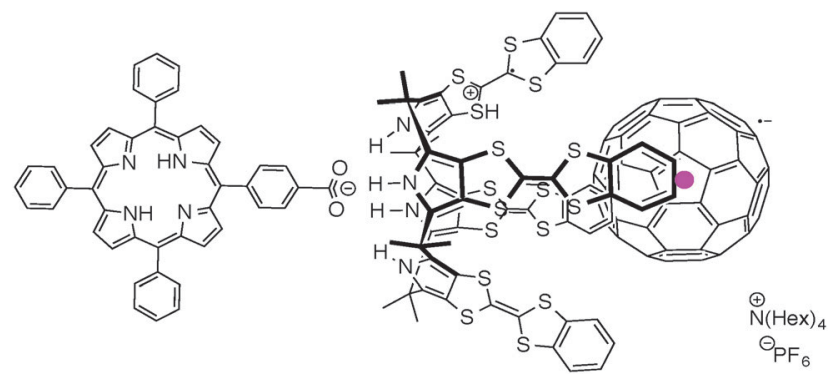

Fig. 2 Supramolecular triad composed of porphyrin carboxylate (1), TTF$\mathrm{C} 4 \mathrm{P}$ radical cation, and $\mathrm{Li}^{+}{ } \mathrm{C}_{60}$ radical anion.

tetra- $n$-hexylammonium $\left(\mathrm{THA}^{+}\right)$porphyrin carboxylate (1) to a PhCN solution of TTF-C4P and $\mathrm{Li}^{+} @ \mathrm{C}_{60}$, however, electron transfer from TTF-C4P and $\mathrm{Li}^{+} @ \mathrm{C}_{60}$ occurs to produce TTF-C4P ${ }^{\bullet+}$ and $\mathrm{Li}^{+} @ \mathrm{C}_{60}{ }^{--}$, as reflected by the appearance of an absorption band at $900 \mathrm{~nm}$ due to TTFC4P $\mathrm{P}^{\circ}$ and one at $1035 \mathrm{~nm}$ due to $\mathrm{Li}^{+} @ \mathrm{C}_{60} 0^{-}$(see Fig. 3a). ${ }^{1,15,16}$ The absorbance at both 900 and $1035 \mathrm{~nm}$ increased with increasing concentration of 1 to reach a constant value at the point where electron transfer is deemed to be complete ( $c$ a. 1 equiv.) as shown in Fig. 3b. The subsequent decrease in the absorption at $1035 \mathrm{~nm}$ in Fig. 3b is attributed to competition for the neutral $\mathrm{Li}^{+} @ \mathrm{C}_{60}{ }^{--}$binding site from the $\mathrm{THA}^{+}$ counter cation of the excess porphyrin carboxylate, 1. This competition has a substantial effect on the electron transfer chemistry that gives rise to the long wavelength optical feature (i.e., formation of $\mathrm{Li}^{+} @ \mathrm{C}_{60}{ }^{--}$).

It is known that $\mathrm{Cl}^{-}$binds to TTF-C4P and induces a conformational change from the so-called 1,3-alternate to the cone conformation due to concerted $\mathrm{NH}$-anion hydrogen bonding interactions. ${ }^{2,16}$ Under conditions of stoichiometric concentrations of $\mathbf{1}$ or in its absence, such a conformational change makes it possible to bind the fullerene substrate and stabilize the radical ion pair involving the TTF-C4P ${ }^{\bullet+}$ host and the bound $\mathrm{Li}^{+} @ \mathrm{C}_{60}{ }^{--}$guest. The observation of effective ET was consistent with strong binding; however, the binding constant could not be determined accurately due to competitive binding with $\mathrm{THA}^{+}$, which leads to a decrease in the $\mathrm{Li}^{+} @ \mathrm{C}_{60}{ }^{--}$absorption upon addition of more than 1 equiv. of $\mathbf{1}$.

The porphyrin anion-induced electron transfer from TTFC4P to $\mathrm{Li}^{+} @ \mathrm{C}_{60}$ did not afford a broad NIR absorption band, which would be expected if the oxidized donor, TTF-C4P $\mathrm{P}^{\bullet}$, was produced as a free radical cation due to the internal formation of a $\pi$-dimer radial cation involving an oxidized $\mathrm{TTF}^{\bullet+}$ moiety
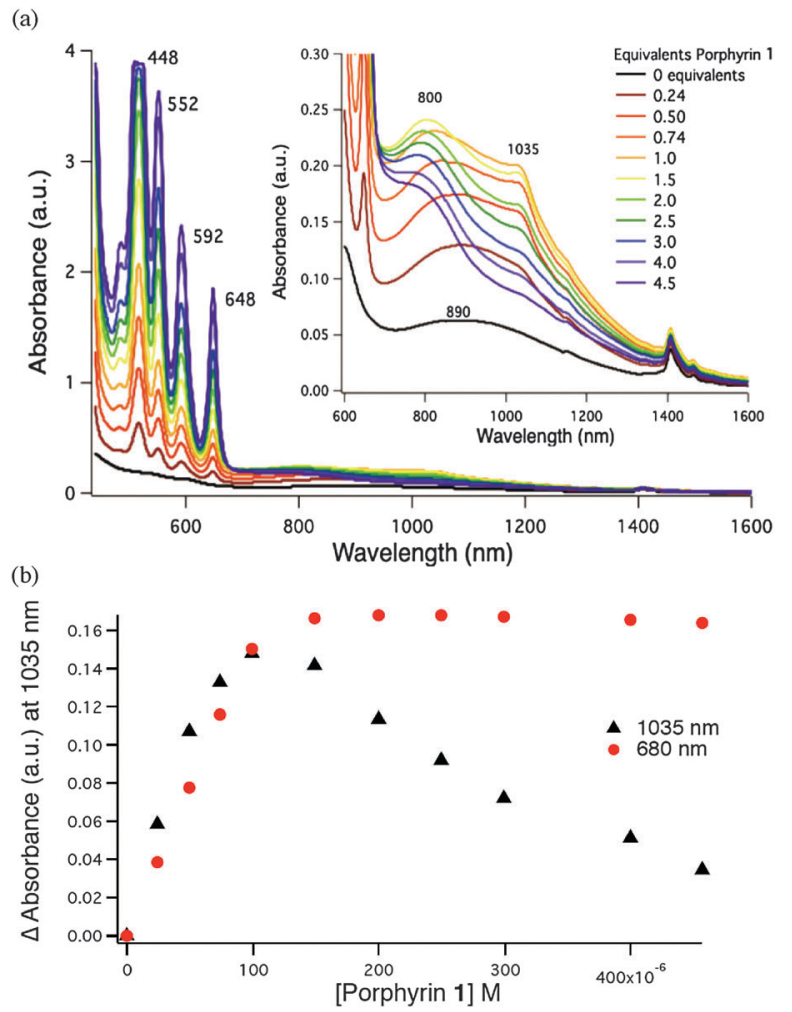

Fig. 3 (a) VIS-NIR spectral changes consistent with electron transfer from TTF-C4P $(100 \mu \mathrm{M})$ to $\mathrm{Li}^{+} \mathrm{aC}_{60}(100 \mu \mathrm{M})$ as seen in the presence of increasing concentrations of 1 in PhCN. Inset: expanded absorption from 600 to $1600 \mathrm{~nm}$. (b) Plots of absorbance at $1035 \mathrm{~nm}$ and $680 \mathrm{~nm}$ vs. concentration of 1 .

and a neutral TTF subunit likewise present in TTF-C4P ${ }^{\bullet+} .{ }^{1}$ The absence of a broad NIR feature thus leads us to suggest that the oxidized host, TTF-C4P ${ }^{\bullet+}$, interacts strongly with the reduced $\mathrm{Li}^{+} @ \mathrm{C}_{60}{ }^{-}$guest to produce the supramolecular charge-separated (CS) complex, 1/TTF-C4 $\mathrm{P}^{{ }^{+}} / \mathrm{Li}^{+} @ \mathrm{C}_{60}{ }^{-}$, wherein the porphyrin component remains in its initial, neutral form.

The EPR spectra recorded after electron transfer from TTF$\mathrm{C} 4 \mathrm{P}$ to $\mathrm{Li}^{+} @ \mathrm{C}_{60}$ in the presence of $\mathbf{1}$ prior to and during photoirradiation are shown in Fig. 4. Here, the signal at $g=$ 2.0064 is ascribed to TTF-C4P $\mathrm{P}^{+}, 2,12 b, 16$ whereas the signal at $g=$ 2.0006 is attributed to the $\mathrm{Li}_{0} \mathrm{C}_{60}$ radical anion. ${ }^{18}$

Upon photoirradiation, a new EPR signal at $g=2.0028$ appears, which is attributed to the radical cation of porphyrin 1. This finding is consistent with our design expectations for this self-assembled triad, namely that upon photoexcitation of the porphyrin, photoinduced electron transfer takes place from the porphyrin to the TTF-C4P radical cation to form a multicomponent, charge-separated complex, $\mathbf{1}^{\circ} / \mathrm{TTF}-\mathrm{C} 4 \mathrm{P} / \mathrm{Li}^{+} @ \mathrm{C}_{60}{ }^{\bullet-}$. This CS state has the charges localized at the two ends of the selfassembled triad. It thus differs dramatically from that obtained in the absence of photoexcitation.

The fate of the triplet excited state $\left({ }^{3} 1^{*}\right)$ in the supramolecular triad was examined by transient absorption spectroscopy following nanosecond laser flash photolysis measurements. Upon nanosecond laser excitation of a deaerated PhCN solution of 1 


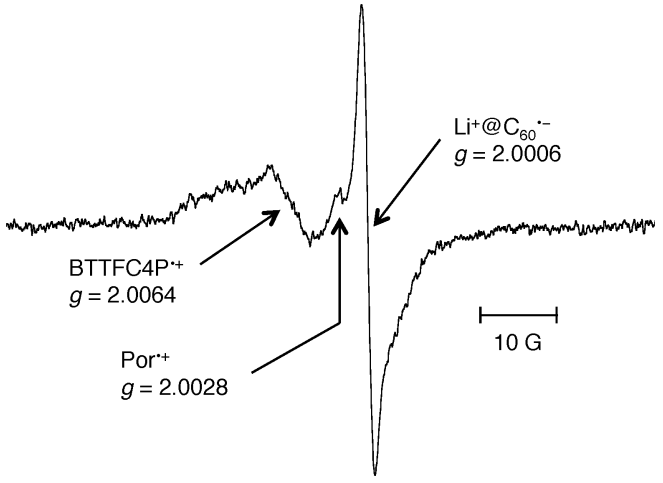

Fig. 4 EPR spectrum of the products of electron transfer from TTF-C4P $(0.1 \mathrm{mM})$ to $\mathrm{Li}^{+} \mathrm{aC} \mathrm{C}_{60}(0.1 \mathrm{mM})$ in the presence of porphyrin $1(0.1 \mathrm{mM})$ in $\mathrm{PhCN}$ at $298 \mathrm{~K}$ after photoirradiation with a high-pressure Hg lamp.

(0.1 mM), TTF-C4P $(0.1 \mathrm{mM})$ and $\mathrm{Li}^{+} @ \mathrm{C}_{60}(0.1 \mathrm{mM})$ at $532 \mathrm{~nm}$, transient absorption bands were observed at $440 \mathrm{~nm}$ and $790 \mathrm{~nm}$ with bleaching at 650 and $720 \mathrm{~nm}$ (Fig. 5a). The absorbance band at $440 \mathrm{~nm}$ is attributed to ${ }^{3} 1^{*}$, which decayed with the increase in the absorption bands at $790 \mathrm{~nm}$ due to $\mathbf{1}^{\mathbf{}^{+}}$ and recovery of bleaching at 650 and $720 \mathrm{~nm}$ due to TTF-C4P ${ }^{\bullet+}$. Such a spectral change indicates that electron transfer from ${ }^{3} \mathbf{1}^{*}$ to TTF-C4P ${ }^{\bullet+}$ occurred to produce the higher energy CS state $\left(\mathbf{1}^{\bullet+} / \mathrm{TTF}-\mathrm{C} 4 \mathrm{P} / \mathrm{Li}^{+} @ \mathrm{C}_{60}{ }^{\bullet-}\right)$. The fact that no changes in the spectral features at $1035 \mathrm{~nm}$ ascribable to $\mathrm{Li}^{+} @ \mathrm{C}_{60}{ }^{--}$are observed under conditions of the transient absorption measurements leads us to conclude that the $\mathrm{Li}^{+}$@ $\mathrm{C}_{60}{ }^{--}$component of the $\mathrm{CS}$ state remains the same in the absence and presence of nanosecond laser excitation. On the other hand, the decay of the transient absorption due to $\mathbf{1}^{\mathbf{}+}$ is consistent with formation of a higher energy CS state wherein the charges reside on the two termini of the self-assembled triad (i.e., $\mathbf{1}^{\bullet+} / \mathrm{TTF}-\mathrm{C} 4 \mathrm{P} / \mathrm{Li}^{+} @ \mathrm{C}_{60}{ }^{\bullet-}$ ). The lifetime of the CS state produced upon photoexcitation is $4.8 \mu \mathrm{s}$, as determined from the absorption recovery of the bleaching band at $650 \mathrm{~nm}$ ascribed to the porphyrin ground state (Fig. 5). The photodynamics of the supramolecular triad are summarized in the energy diagram given in Scheme 1.

In conclusion, binding of a porphyrin anion (1) to TTF-C4P results in electron transfer from TTF-C4P to $\mathrm{Li}^{+} @ \mathrm{C}_{60}$ to produce
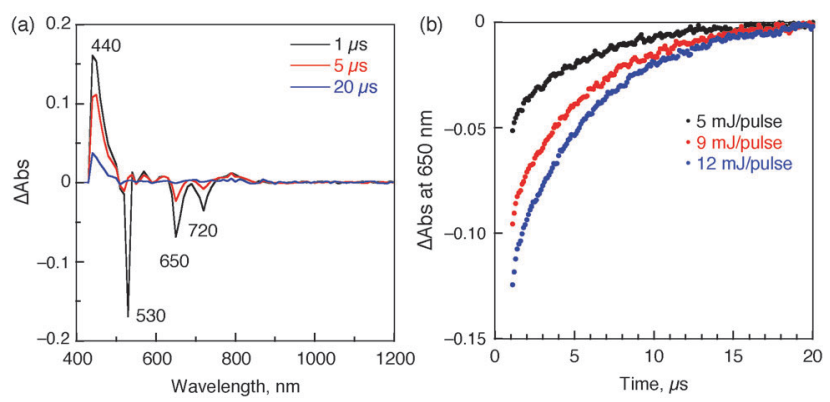

Fig. 5 (a) Nanosecond flash photolysis absorption spectra for a mixture of $1(100 \mu \mathrm{M}), \mathrm{TTF}-\mathrm{C} 4 \mathrm{P}(100 \mu \mathrm{M})$ and $\mathrm{Li}^{+} \mathrm{aC}_{60}(100 \mu \mathrm{M})$ following excitation at $532 \mathrm{~nm}$ in deoxygenated PhCN at $298 \mathrm{~K}$ as recorded $1 \mu \mathrm{s}$ (black), $5 \mu \mathrm{s}$ (red), and $20 \mu \mathrm{s}$ (blue) after laser pulse irradiation. (b) Decay time profiles of the absorbance at $650 \mathrm{~nm}$ obtained using various laser intensities.

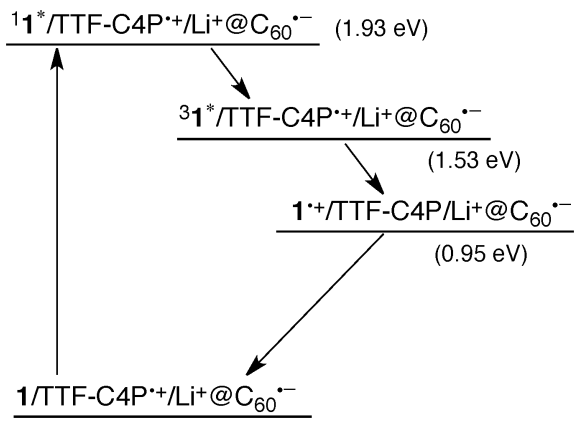

Scheme 1

the supramolecular charge-separated triad (1/TTF-C4P $\left.{ }^{\bullet+} / \mathrm{Li}^{+} @ \mathrm{C}_{60}{ }^{\bullet-}\right)$. Photoexcitation of the porphyrin component (1) within the supramolecular triad leads first to the production of an excited singlet state $\left({ }^{1} \mathbf{1}^{*}\right)$ and intersystem crossing from ${ }^{1} \mathbf{1}^{*}$ to ${ }^{3} \mathbf{1}^{*}$, from which electron transfer to $\mathrm{TTF}-\mathrm{C} 4 \mathrm{P}^{\bullet+}$ occurs to produce the higher energy charge-separated sate $\left(\mathbf{1}^{{ }^{+}} / \mathrm{TTF}-\mathrm{C} 4 \mathrm{P} / \mathrm{Li}^{+} @ \mathrm{C}_{60}{ }^{\bullet-}\right)$. The CS lifetime of the latter state was determined to be $4.8 \mu \mathrm{s}$. The present study provides a new approach to creating noncovalent, multi-component systems that support the formation of photoinduced charge separated states. Specifically, we detail the construction of supramolecular electron donor-acceptor ensembles via a combination of anion recognition and donoracceptor interactions and show that it leads to the formation of a well-defined CS state upon photoexcitation. The use of orthogonal recognition motifs is likely to prove to be useful in the preparation of other higher order self assembled ensembles wherein the electronic nature and special arrangement of the individual photo- and redox active components need to be controlled.

This work was supported by Grant-in-Aid (No. 26620154 and 266288037 to K.O.) from the Ministry of Education, Culture, Sports, Science and Technology (MEXT), Japan, and ALCA and SENTAN programs from Japan Science Technology Agency (JST) (to S.F.), JSPS Fellows (25627 to Y.K.), Japan, a U.S. NSF grant (CHE 1057904 to J.L.S), and the Robert A. Welch Foundation (grant F-1018 to J.L.S.).

\section{Notes and references}

1 N. L. Bill, O. Trukhina, J. L. Sessler and T. Torres, Chem. Commun., 2015, 51, 7781.

2 S. Fukuzumi, K. Ohkubo, Y. Kawashima, D. S. Kim, J. S. Park, A. Jana, V. M. Lynch, D. Kim and J. L. Sessler, J. Am. Chem. Soc., 2011, 133, 15938.

3 C. M. Davis, Y. Kawashima, K. Ohkubo, J. M. Lim, D. Kim, S. Fukuzumi and J. L. Sessler, J. Phys. Chem. C, 2014, 118, 13503.

4 (a) D. Gust, T. A. Moore and A. L. Moore, Acc. Chem. Res., 2001, 34, 40; (b) D. Gust, T. A. Moore and A. L. Moore, Acc. Chem. Res., 2009, 42, 1890.

5 (a) M. R. Wasielewski, Acc. Chem. Res., 2009, 42, 1910; (b) F. D. Lewis, R. L. Letsinger and M. R. Wasielewski, Acc. Chem. Res., 2001, 34, 159.

6 (a) M. D. Kaerkaes, E. V. Johnston, O. Verho and B. Åkermark, Acc. Chem. Res., 2014, 47, 100; (b) J. H. Alstrum-Acevedo, M. K. Brennaman and T. J. Meyer, Inorg. Chem., 2005, 44, 6802; (c) J. J. Concepcion, R. L. House, J. M. Papanikolas and T. J. Meyer, Proc. Natl. Acad. Sci. U. S. A., 2012, 109, 15560.

7 (a) S. Kirner, M. Sekita and D. M. Guldi, Adv. Mater., 2014, 26, 1482; (b) G. de la Torre, G. Bottari, M. Sekita, A. Hausmann, D. M. Guldi and T. Torres, Chem. Soc. Rev., 2013, 42, 8049; (c) D. M. Guldi, Phys. 
Chem. Chem. Phys., 2007, 9, 1400; (d) D. M. Guldi, Chem. Soc. Rev., 2002, 31, 22; (e) J. Malig, N. Jux and D. M. Guldi, Acc. Chem. Res., 2013, 46, 53.

8 (a) S. Fukuzumi, Org. Biomol. Chem., 2003, 1, 609; (b) S. Fukuzumi, Phys. Chem. Chem. Phys., 2008, 10, 2283; (c) S. Fukuzumi and T. Kojima, J. Mater. Chem., 2008, 18, 1427; (d) S. Fukuzumi and K. Ohkubo, J. Mater. Chem., 2012, 22, 4575; (e) S. Fukuzumi, K. Ohkubo and T. Suenobu, Acc. Chem. Res., 2014, 47, 1455.

9 (a) F. D'Souza and O. Ito, Chem. Soc. Rev., 2012, 41, 86; (b) F. D'Souza and O. Ito, Chem. Commun., 2009, 4913; (c) F. D'Souza and O. Ito, Coord. Chem. Rev., 2005, 249, 1410; (d) M. E. El-Khouly, S. Fukuzumi and F. D'Souza, ChemPhysChem, 2014, 15, 30.

10 (a) S. Fukuzumi, K. Ohkubo, F. D'Souza and J. L. Sessler, Chem. Commun., 2012, 48, 9801; (b) S. Fukuzumi and K. Ohkubo, Dalton Trans., 2013, 42, 1584.

11 (a) Y. Kawashima, K. Ohkubo and S. Fukuzumi, Chem. - Asian J., 2015, 10, 44; (b) M. Supur, Y. Kawashima, K. R. Larsen, K. Ohkubo, J. O. Jeppesen and S. Fukuzumi, Chem. - Eur. J., 2014, 20, 13976; (c) M. Supur, Y. Kawashima, Y.-X. Ma, K. Ohkubo, C.-F. Chen and S. Fukuzumi, Chem. Commun., 2014, 50, 15796.

12 (a) Y. Kawashima, K. Ohkubo, K. Mase and S. Fukuzumi, J. Phys. Chem. C, 2013, 117, 21166; (b) N. L. Bill, M. Ishida, S. Bahring, J. M. Lim, S. Lee, C. M. Davis, V. M. Lynch, K. A. Nielsen,
J. O. Jeppesen, K. Ohkubo, S. Fukuzumi, D. Kim and J. L. Sessler, J. Am. Chem. Soc., 2013, 135, 10852.

13 N. L. Bill, M. Ishida, Y. Kawashima, K. Ohkubo, Y. M. Sung, V. M. Lynch, J. M. Lim, D. Kim, J. L. Sessler and S. Fukuzumi, Chem. Sci., 2014, 5, 3888.

14 (a) K. Ohkubo, K. Mase, E. Karnas, J. L. Sessler and S. Fukuzumi, J. Phys. Chem. C, 2014, 118, 18436; (b) J. L. Sessler, E. Karnas, S. K. Kim, Z. Ou, M. Zhang, K. M. Kadish, K. Ohkubo and S. Fukuzumi, J. Am. Chem. Soc., 2008, 130, 15256.

15 For supramolecuar triads and tetrads in which covalently linked dyads and triads are used, see: $(a)$ F. D'Souza, A. N. Amin, M. E. El-Khouly, N. L. Subbaiyan, M. E. Zandler and S. Fukuzumi, J. Am. Chem. Soc., 2012, 134, 654; (b) P. Mondal, A. Chaudhary and S. P. Rath, Dalton Trans., 2013, 42, 12381; (c) V. Bandi, M. E. El-Khouly, K. Ohkubo, V. N. Nesterov, M. E. Zandler, S. Fukuzumi and F. D'Souza, J. Phys. Chem. C, 2014, 118, 2321.

16 J. S. Park, E. Karnas, K. Ohkubo, P. Chen, K. M. Kadish, S. Fukuzumi, C. Bielawski, T. W. Hudnall, V. M. Lynch and J. L. Sessler, Science, 2010, 329, 1324.

17 Y. Kawashima, K. Ohkubo and S. Fukuzumi, J. Phys. Chem. A, 2012, 116, 8942.

18 K. Ohkubo, Y. Kawashima and S. Fukuzumi, Chem. Commun., 2012, 48, 4314 . 